\title{
Development of a Mouse Model for Chronic Cat Allergen-Induced Asthma
}

\author{
Jeanette Grundström ${ }^{a}$ Tiiu Saarne ${ }^{a}$ Cecilia Kemi ${ }^{b, c}$ Joshua A. Gregoryb,c \\ Konrad Wadén ${ }^{a}$ Marina C. Pils ${ }^{e}$ Mikael Adner ${ }^{b, c}$ Guro Gafvelin ${ }^{a, d}$ \\ Marianne van Hage ${ }^{a}$ \\ ${ }^{a}$ Clinical Immunology and Allergy Unit, Department of Medicine Solna, Karolinska Institutet, Karolinska University \\ Hospital, ${ }^{b}$ Experimental Asthma and Allergy Research, Institute of Environmental Medicine, ${ }^{c}$ Centre for Allergy \\ Research and ${ }^{d}$ Department of Clinical Neuroscience, Therapeutic Immune Design Unit, Stockholm, Sweden; ${ }^{\mathrm{e}}$ Mouse \\ Pathology, Animal Experimental Unit, Helmholtz Centre for Infection Research, Braunschweig, Germany
}

\section{Key Words}

Asthma · Allergy · Mouse model · Cat allergen · Fel d 1

\begin{abstract}
Background: Allergic asthma is a chronic inflammatory airway disease caused by exposure to airborne allergens. In order to develop novel therapies for allergic asthma, models that are relevant to human disease are needed. Methods: Female BALB/c mice were presensitised subcutaneously with alum-adsorbed recombinant cat allergen Fel d 1, followed by intranasal challenges with cat dander extract spiked with recombinant Fel d 1 for 7 weeks. For reference, mice were presensitised and challenged with ovalbumin following the same protocol. Airway hyperresponsiveness, serum antibodies, airway inflammation and cell infiltration, and cytokines in lung tissue and bronchoalveolar lavage were measured. Results: Mice presensitised with recombinant Fel $d 1$ and challenged with cat dander extract or presensitised and challenged with ovalbumin showed airway hyperresponsiveness in response to metacholine. Mice of the cat allergen model showed influx of neutrophils, eosinophils and lymphocytes in bronchoalveolar lavage, combined with increased levels of IL-17a and increased IL-4 mRNA expression in lung tissue. In contrast, mice sensitised and chal-
\end{abstract}

lenged with ovalbumin showed a predominant influx of eosinophils in bronchoalveolar lavage and had an increased expression of IL-5 in lung tissue. Both protocols induced features of lung tissue remodelling and allergen-specific antibody responses. Conclusions: The presented mouse model for cat allergen-induced asthma exhibits hallmarks of chronic allergic asthma, like airway hyperresponsiveness, a mixed neutrophilic/eosinophilic infiltration in bronchoalveolar lavage, expression of IL-17a and signs of remodelling in lung tissue. The model will provide a relevant platform for the development of novel treatment strategies.

ㄷ) 2014 S. Karger AG, Basel

\section{Introduction}

Allergic asthma is a chronic inflammatory airway disease characterised by airway hyperreactivity to allergens. Patients with allergic asthma most often receive symptomatic treatment. However, allergen-specific immunotherapy (ASIT), also referred to as allergy vaccination, has

J.G. and T.S. share first authorship; G.G. and M.v.H. share last authorship.

\section{KARGER}

E-Mail karger@karger.com

www.karger.com/iaa
(C) 2014 S. Karger AG, Basel

$1018-2438 / 14 / 1653-0195 \$ 39.50 / 0$
Correspondence to: Prof. Marianne van Hage

Department of Medicine, Clinical Immunology and Allergy Unit

Karolinska Institutet, Karolinska University Hospital L2:04

SE-171 76 Stockholm (Sweden)

E-Mail marianne.van.hage@ki.se 
been proven to be clinically effective in the treatment for allergic asthma [1]. ASIT is the only disease-modifying treatment available today and has both the ability to reduce allergic inflammation and to protect against development into chronic disease [2]. However, the treatment is both time consuming and resource demanding, and is linked to the risk of adverse side effects [3]. In order to make the treatment attractive for more patients that would benefit from ASIT, new treatment strategies are currently being investigated $[4,5]$. An important step in the development of novel allergy therapies is to show preclinical proof-of-concept in relevant allergy and asthma models.

A large number of protocols for sensitisation and allergen challenge have been developed in mice using the model allergen chicken ovalbumin (OVA) [6]. The relevance of these models to human allergic disease and asthma has, however, been questioned [7-9]. The criticisms are centered primarily around the facts that mice do not spontaneously develop asthma, OVA is not a naturally inhaled allergen, the experimental sensitisation route is often parenteral and not via the airways, and the protocols are usually short and result in an acute and transient form of airway response. Recently, both improved chronic OVA protocols [10] and protocols with relevant inhaled allergens (e.g. dust mite, pollen and moulds [1114]) have been developed. Chronic asthma models have been employed in a number of studies of disease and treatment mechanisms $[12,14-18]$, but there is still a need for improved models of allergy and asthma induced by allergens relevant for human disease.

Cat allergens carried by cat dander and hair are important triggers of asthma. For example, cat allergy is the most common cause of asthma among Swedish children $[19,20]$, and a study in 2006 showed that almost $20 \%$ of school children in northern Sweden were sensitised to cat [21]. Thus, allergy to cat is a particularly relevant model for studying allergic asthma. In addition, more than $90 \%$ of patients sensitised to cat react to the major cat allergen Fel d 1 [22]. This makes Fel d 1 an ideal target for investigating novel strategies for ASIT [23]. We have previously established a mouse model for cat allergy which we have applied to the evaluation of novel Fel d 1-based ASIT strategies [24-27]. The model reflects the acute phase of allergic disease and involves three biweekly subcutaneous (s.c.) sensitisations with recombinant ( $r$ ) Fel d 1, followed by three intranasal (i.n.) challenges with cat dander extract (CDE) during 1 week [24]. Here we aimed to establish a relevant chronic model for cat allergen-induced asthma, exhibiting increased airway hyperresponsiveness (AHR) and signs of lung tissue remodelling. The model will be used for further evaluation of the effects of existing Fel $\mathrm{d} 1$ vaccines on asthma, as well as for the investigation of new Fel d 1 ASIT candidates.

\section{Materials and Methods}

\section{Animals}

Female BALB/c mice (8-10 weeks of age) were obtained from Charles River (Sulzfeld, Germany) and housed with food and water ad libitum. The experiments were approved by the Swedish local ethics committee for animal welfare.

\section{Antigens}

$\mathrm{CDE}$ and $\mathrm{rFel} \mathrm{d} 1$ were prepared as previously described [24, 28]. Protein concentrations were determined by BCA protein assay (Pierce, Rockford, Ill., USA). The CDE contained $200 \mathrm{ng}$ of Fel $\mathrm{d} 1 / \mathrm{mg}$ protein as determined by a Fel d 1 ELISA kit (Indoor Biotechnologies, Charlottesville, Va., USA). OVA grade II was purchased from Sigma-Aldrich (Steinheim, Germany). The CDE endotoxin concentration ranged from 96.2 to $410 \mathrm{ng} / \mathrm{mg}$ protein, while rFel $\mathrm{d} 1$ and OVA preparations contained 1.7 and $35.5 \mathrm{ng}$ of endotoxin/mg protein, respectively (Limulus amebocyte lysate Endochrome assay; Charles River Endosafe, Charleston, S.C., USA).

\section{Sensitisation and Challenge Protocol}

An initial experiment was designed to evaluate lung tissue remodelling. In this protocol, mice ( $n=4$ /group) were presensitised by s.c. injection with $1 \mu \mathrm{g}$ of rFel d 1 or $10 \mu \mathrm{g}$ of OVA adsorbed to $1 \mathrm{mg}$ of alum (Sigma-Aldrich) in $200 \mu \mathrm{l}$ of PBS on day -14 and -7 , followed by i.n. challenge with $50 \mu \mathrm{g}$ of CDE plus $1 \mu \mathrm{g}$ of $\mathrm{rFel} \mathrm{d} 1$ (CDE challenge) or $100 \mu \mathrm{g}$ of OVA ( $\mathrm{rFel} \mathrm{d} 1$ and OVA-sensitised mice, respectively) in a volume of $25 \mu$, every second day, 3-times per week for 6 weeks (protocol 1, fig. 1a) following light anaesthesia. Control mice were presensitised with $1 \mu \mathrm{g}$ of rFel d 1 and challenged with $25 \mu$ l of PBS. On day 43, lungs were taken and embedded in paraffin for tissue remodelling analyses.

In the main protocol, groups of mice ( $n=8$ /group) were presensitised and challenged i.n. as described above, but the challenges were performed on 3 consecutive days per week for 7 weeks (protocol 2; fig. 1b). On day 44, AHR measurements were performed, followed by the collection of bronchoalveolar lavage (BAL) fluid, blood, lung and spleen.

\section{Measurement of Airway Responsiveness}

On day 44 of the main protocol (fig. 1b), AHR was induced by administration of methacholine (MCh; Sigma-Aldrich) in mice anaesthetised with hypnorm $(2.5 \mu \mathrm{l} / \mathrm{g}$; VetaPharma Ltd., Leeds, $\mathrm{UK}$ ) and midazolam (12.5 $\mu \mathrm{g} / \mathrm{g}$; Hameln Pharmaceuticals GmbH, Hameln, Germany). The MCh was delivered by aerosol administration via a nebuliser (Scireq; Montreal, Que., Canada), $10 \mu \mathrm{l} /$ dose at doses ranging from 15 to $500 \mathrm{mg} / \mathrm{ml}$ after an initial dose of PBS alone. The AHR was measured with a small animal ventilator (FlexiVent; Scireq), as previously described [24]. Dynamic and central resistance ( $R$ and $R n$, respectively), central airway compliance $(\mathrm{C})$, peripheral tissue damping $(\mathrm{G})$ and tissue elastance $(\mathrm{H})$ were recorded. The Newtonian resistance, $\mathrm{Rn}$, is a close approximation of resistance in the central airways, tissue damp- 


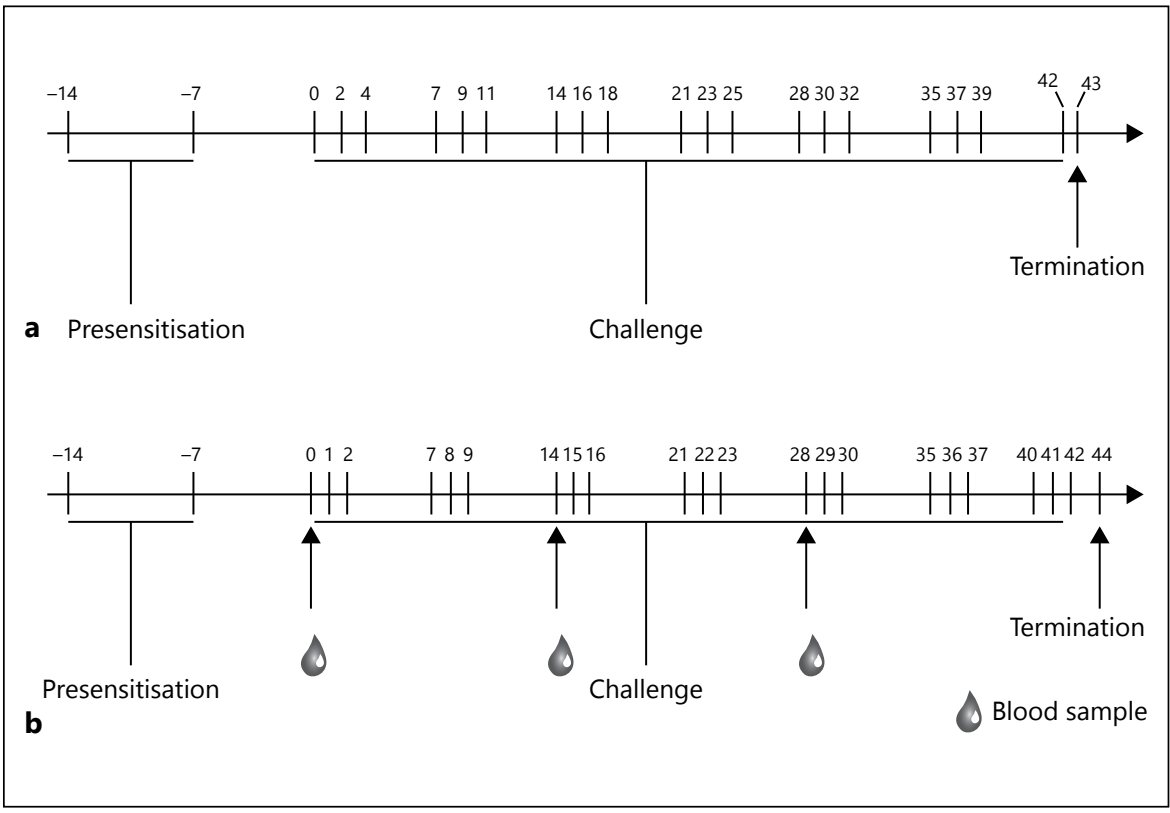

Fig. 1. Presensitisation and challenge proresponses. b Protocol 2: main protocol.

ing reflects energy dissipation in the lung tissue, and tissue elastance characterises tissue stiffness and reflects energy storage in the tissue.

\section{Bronchoalveolar Lavage}

BAL was performed essentially as previously described [26]. Lungs were lavaged three times with a volume of $0.8 \mathrm{ml}$ of PBS. Total numbers of cells were counted and cells were cytospun and stained with May Grünwald-Giemsa (Sigma-Aldrich) for differential counts of a minimum of 300 cells per slide.

\section{Lung Tissue}

The lobes of the right lung were separated from the heart and left lung, snap-frozen in liquid nitrogen and stored at $-80^{\circ} \mathrm{C}$. The left lung was either fixed by inflation with $4 \%$ formaldehyde (Sigma-Aldrich) for $24 \mathrm{~h}$ and washed with ethanol (protocol 1), or subjected to dehydration with ethanol (protocol 2), prior to storage in $70 \%$ ethanol at $4^{\circ} \mathrm{C}$. The lungs were then processed for histological analysis and embedded in paraffin for sectioning. Lung tissue extracts were made by homogenising one half of the right lung lobes using a Bio-Plex cell lysis kit (BioRad, Solna, Sweden), and the other half in RLT buffer (Qiagen, Hilden, Germany) followed by homogenisation with a Precellys 24 homogeniser (Bertin Technologies, Montigny-le-Bretonneux, France) using CK28 beads and the $2 \times 20 \mathrm{~s}$ shaking program. The tissue homogenates in cell lysis buffer were centrifuged, and the supernatants and RLT homogenates were stored at $-80^{\circ} \mathrm{C}$ until analysis.

\section{Lung Histology}

Paraffin-embedded lung sections from mice subjected to protocol 1 (fig. 1a) were stained with hematoxylin and eosin (HE) and combined periodic acid-Schiff/Alcian blue reaction (PAS) according to standard protocol. Masson's trichrome staining was performed using a Masson-Goldner Trichrome staining kit (Carl Roth GmbH, Karlsruhe, Germany). Histopathological evaluation was done blinded to the experimental groups. The degree of inflammatory cell infiltration was graded on HE-stained sections from protocol $1(0=$ no alteration, $1=$ mild, $2=$ moderate, $3=$ severe). The amount of inflammatory infiltrate and the quantity of macrophages and other detritus in alveoli were graded from 0 to 3 $(0=$ no inflammation, $1=$ low, $2=$ moderate, $3=$ high $)$. The area involved in lesions was estimated as follows: $0=0 \%, 1=0-30 \%$, $2=30-70 \%, 3=$ everything exceeding $70 \%$. A total inflammation score was obtained by summarising the scores from the HE evaluation, generating a theoretical maximal lung inflammation score of 12. The number of goblet cells were estimated in PAS-stained sections according to the following criteria: $0=$ no goblet cells present, $1=$ up to 5 goblet cells per bronchus, $2=5-20$ goblet cells per bronchus up to a total of $50 \%$ of bronchial epithelium, $3=$ more than $50 \%$ of bronchial epithelium. Increases in peribronchial and perivascular connective tissue were estimated in Masson's trichrome-stained sections: $0=$ no alteration, $1=$ thickening of $<30 \%$ of all bronchial and arterial walls visible, $2=$ thickening of $30-70 \%$ of bronchial and arterial walls visible, $3=$ thickening of $>70 \%$ of the arterial and bronchial walls visible. Paraffin-embedded lung sections from mice subjected to the main protocol (protocol 2; fig. 1b) were stained with HE and PAS, and semiquantitatively evaluated on a $0-3$ scale: $0=$ no sign of inflammation/mucus cells, 3 = massive inflammatory cell infiltrate/epithelium almost completely covered with mucus cells. One investigator evaluated all histological sections from the same protocol.

\section{Cytokine Analyses}

Samples from lung tissue extracts were analysed for IL-5 and IFN- $\gamma$ by ELISA (Mabtech, Nacka, Sweden), and for IL-17a by Luminex (Milliplex; Merck-Millipore, Billerica, Mass., USA) according to the manufacturers' instructions. Luminex data were recorded with a Lumine $\times 200$ (Luminex, Austin, Tex., USA).

Extraction of mRNA from lung tissue samples was performed with an RNeasy mini kit (Qiagen) and cDNA was ampli- 
fied using a first strand cDNA synthesis kit (Fermentas; Thermo Fisher Scientific, Waltham, Mass., USA) with random hexamers. Analysis with qPCR was performed for GAPDH (forward 5'-GAA GGT CGG TGT GAA CGG-3', reverse 5'-CTC GCT CCT GGA AGA TGG-3'), IL-4 (forward 5'-GGT CTC AAC CCC CAG CTA- $3^{\prime}$, reverse $5^{\prime}$-AAA TAT GCG AAG CAC CTT GG-3'), IL-5 (forward 5'-CTC TGT TGA CAA GCA ATG AGA CG-3', reverse 5'-TCT TCA GTA TGT CTA GCC CCT G-3'), IL17a (forward 5'-CCA GAA GGC CCT CAG ACT-3', reverse 5'TTC TCG ACC CTG AAA GTG AA- $3^{\prime}$ ) and IFN- $\gamma$ (forward $5^{\prime}$-TTG AAG TCT TGA AAG ACA ATC A-3', reverse $5^{\prime}$-AGC GAC TCC TTT TCC GCT T- $3^{\prime}$ ) using a SYBRgreen kit (BioRad). Relative expression was calculated as $1 / \Delta \mathrm{Ct} \cdot 100$, with GAPDH as the reference gene.

\section{Allergen-Specific Antibody Levels}

Blood was collected by cardiac puncture on the final day of the protocol and sera were stored at $-20^{\circ} \mathrm{C}$. Ninety-six-well plates (Nunc, Roskilde, Denmark) were coated with $5 \mu \mathrm{g} / \mathrm{ml}$ of $\mathrm{rFel} \mathrm{d} 1$, $5 \mu \mathrm{g} / \mathrm{ml}$ of OVA or $2 \mu \mathrm{g} / \mathrm{ml}$ of rat anti-mouse IgE (BD Pharmingen). Sera were diluted 1:20 for IgE, 1:1,000 for IgG2a, and within a range of $1: 10,000$ to $1: 1,000,000$ for IgG1 due to differences in titers. A reference serum was used as an internal standard to measure IgG1 (AU/ml). Bound immunoglobulins were detected as described previously [26]. To allow comparisons between the groups, the samples from the different groups were measured on the same plate for each isotype.

\section{Statistical Analysis}

The results are expressed as median \pm interquartile range and were analysed by Mann-Whitney U test using GraphPad Prism version 5 for Windows (GraphPad Software Inc., San Diego, Calif., USA). $\mathrm{p}<0.05$ was considered statistically significant. Comparisons were performed versus PBS but not between the cat allergen and OVA models. No statistical comparison was made between the OVA group and PBS group for the immunoglobulin measurements as different ELISAs were used for the different antigens.

\section{Results}

\section{Lung Tissue Remodelling}

In a protocol set up to optimise the airway challenge schedule, the lung tissue was carefully examined for inflammation and tissue remodelling. Mice were presensitised s.c. with rFel d 1 or OVA and challenged i.n. with CDE or OVA every other day, 3 days per week for 7 weeks (protocol 1; fig. 1a). The CDE- and OVA-challenged mice exhibited higher total inflammation scores than the PBS controls (fig. 2a). Representative HE-stained sections are shown in figure $2 \mathrm{~b}$. Plasma cells were the predominating cells in inflammatory infiltrates of OVA-challenged mice. In the other groups, granulocytes were most prevalent. In CDE- and OVA-challenged animals, multinuclear macrophages were observed in alveoli. Furthermore, the CDE- and OVA-challenged mice had higher scores com- pared to PBS controls for PAS and Masson's trichrome staining, although the scores varied in the actively challenged mice (fig. 2a). Increased peribronchial and perivascular deposition of collagen was observed in CDE- and OVA-challenged mice, with a tendency towards a higher score in the OVA group. Representative sections of PAS staining and Masson's trichrome staining are presented in figure $2 c$ and $d$, respectively. These data support the notion that mice chronically challenged with either CDE or OVA exhibit features of inflammation and tissue alteration typical of allergic asthma.

\section{Repeated Intranasal Exposure to CDE Increases AHR}

In order to increase the airway response compared to the remodelling protocol, mice of the main protocol were challenged i.n. for 7 weeks on 3 consecutive days per week followed by 4 days of rest (protocol 2; fig. 1b). Although a few mice in each of the groups challenged with CDE did not exhibit increased dynamic and central resistance to aerosolised $\mathrm{MCh}$, the results clearly show that the group of CDE-challenged mice had elevated dynamic and central resistance values compared to PBS-challenged controls ( $\mathrm{p}<0.05$; fig. $3 \mathrm{a}-\mathrm{c})$. The group of CDE-challenged mice also exhibited decreased airway compliance and increased tissue damping compared to PBS-challenged mice ( $\mathrm{p}<0.01$ and 0.05 , respectively; fig. $3 \mathrm{~d}, \mathrm{e})$. Mice presensitised and challenged with OVA had increased dynamic resistance, tissue damping and tissue elastance, and decreased compliance $(\mathrm{p}<0.001$; fig. $3 \mathrm{~b}, \mathrm{~d}-\mathrm{f})$. The central resistance was also increased, although for some mice this parameter was similar to the PBS-challenged mice ( $\mathrm{p}<0.01$; fig. $3 \mathrm{c}$ ). Thus, with this protocol airway challenge with CDE, as well as with OVA, increases AHR in the central and peripheral airways, and impairs lung inflation capacity.

\section{The Airway Inflammatory Response Differs between} CDE- and OVA-Challenged Mice

Airway challenge with CDE in $\mathrm{rFel} \mathrm{d} 1$ presensitised mice, and with OVA in OVA presensitised mice, led to a decrease in the proportion of macrophages in total BAL cells compared to PBS challenge (data not shown), although the total number of macrophages was not changed (fig. 4a). The number of lymphocytes, eosinophils and neutrophils were elevated in CDE-challenged mice compared to PBS-challenged mice ( $\mathrm{p}<0.01$ for lymphocytes and eosinophils, $\mathrm{p}<0.001$ for neutrophils; fig. $4 \mathrm{~b}-\mathrm{d}$ ). OVA-challenge resulted in increased numbers of eosinophils, lymphocytes ( $<<0.001$; fig. $4 \mathrm{~b}, \mathrm{c}$ ) and neutrophils ( $p<0.05$; fig. $4 \mathrm{~d}$ ). Histological analysis of HE-stained 


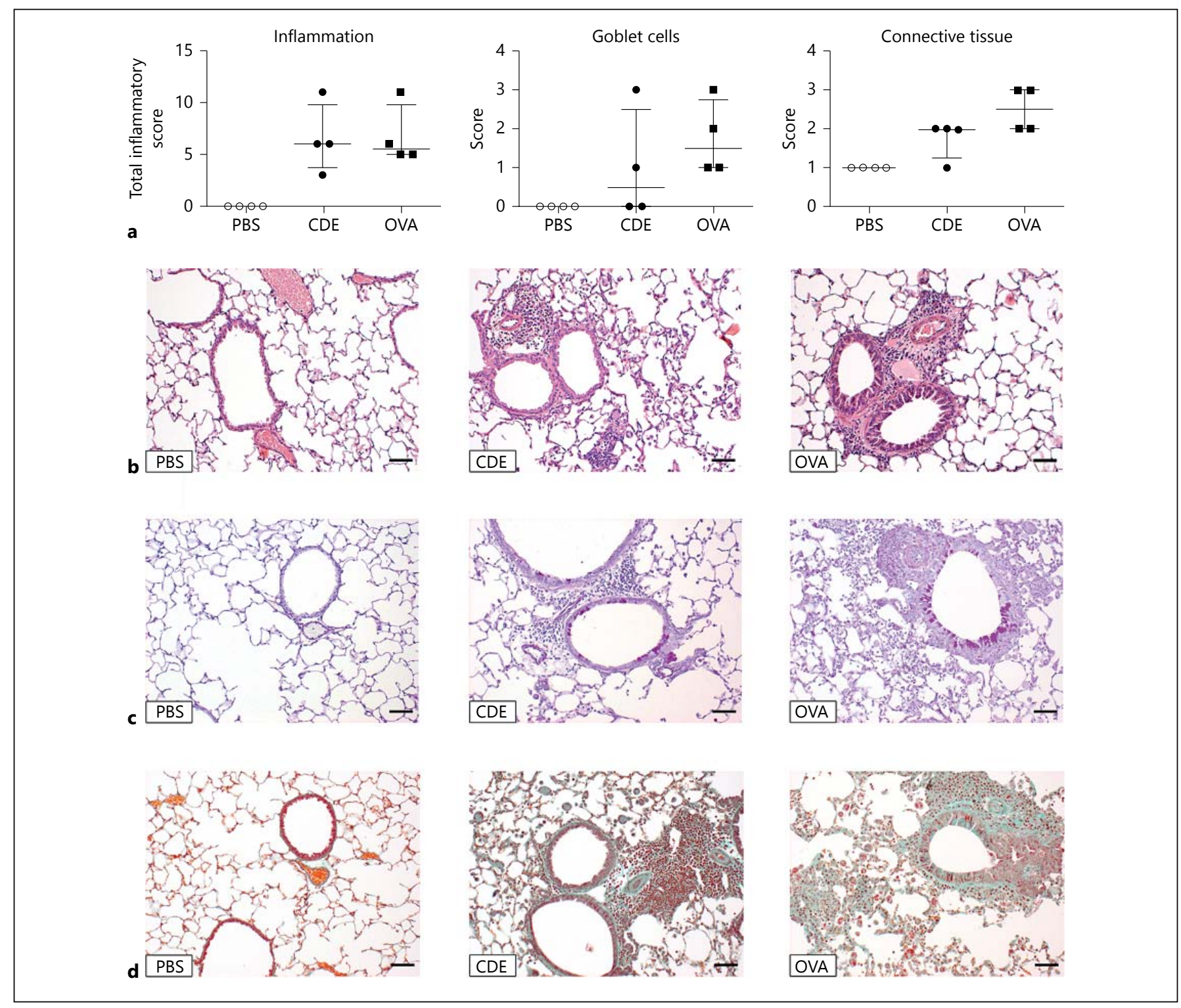

Fig. 2. Inflammation and tissue remodelling in lungs from mice subjected to protocol $1(\mathrm{n}=4)$. a Total inflammation score based on the sum of scores ( $\max$ score $=12$ ) for the degree of inflammatory cell infiltration, amount of inflammatory infiltrate, and of macrophages and the area involved in lesions in HE-stained sections (left). On PAS-stained sections the number of goblet cells was estimated (middle). Peribronchial and perivascular connective tissue was analysed in Masson's trichrome-stained sections (right). Representative sections from PBS-, CDE- and OVA-challenged mice stained with HE (b), PAS (c) and Masson's trichrome (d). Scale bar $=50 \mu \mathrm{m}$.

increases were significant compared to PBS-challenged mice ( $\mathrm{p}<0.01, \mathrm{CDE} ; \mathrm{p}<0.001$, OVA; fig. 4g, h).

Analysis of the cytokine profile in lung tissue revealed that mice challenged with $C D E$ had an increased expression of IL-4 mRNA ( $p<0.05)$, but they did not show a significantly increased expression of IL-5 protein or mRNA compared to PBS-challenged mice (fig. 5a). OVA-challenged mice had elevated IL-5 levels 
Fig. 3. AHR in response to $\mathrm{MCh}$ challenge in mice subjected to the main protocol $(\mathrm{n}=$ 5-8). a Dynamic resistance (R) in response to increasing doses of MCh. The maximum response, regardless of dose, for each parameter is presented: $\mathrm{R}(\mathbf{b})$, central resistance $(\mathrm{Rn} ; \mathbf{c})$, compliance $(\mathrm{C} ; \mathbf{d})$, tissue damping $(\mathrm{G} ; \mathbf{e})$ and tissue elastance $(\mathrm{H} ; \mathbf{f})$. Mann-Whitney U test; ${ }^{*} \mathrm{p}<0.05,{ }^{* *} \mathrm{p}<$ $0.01,{ }^{* * *} \mathrm{p}<0.001$.

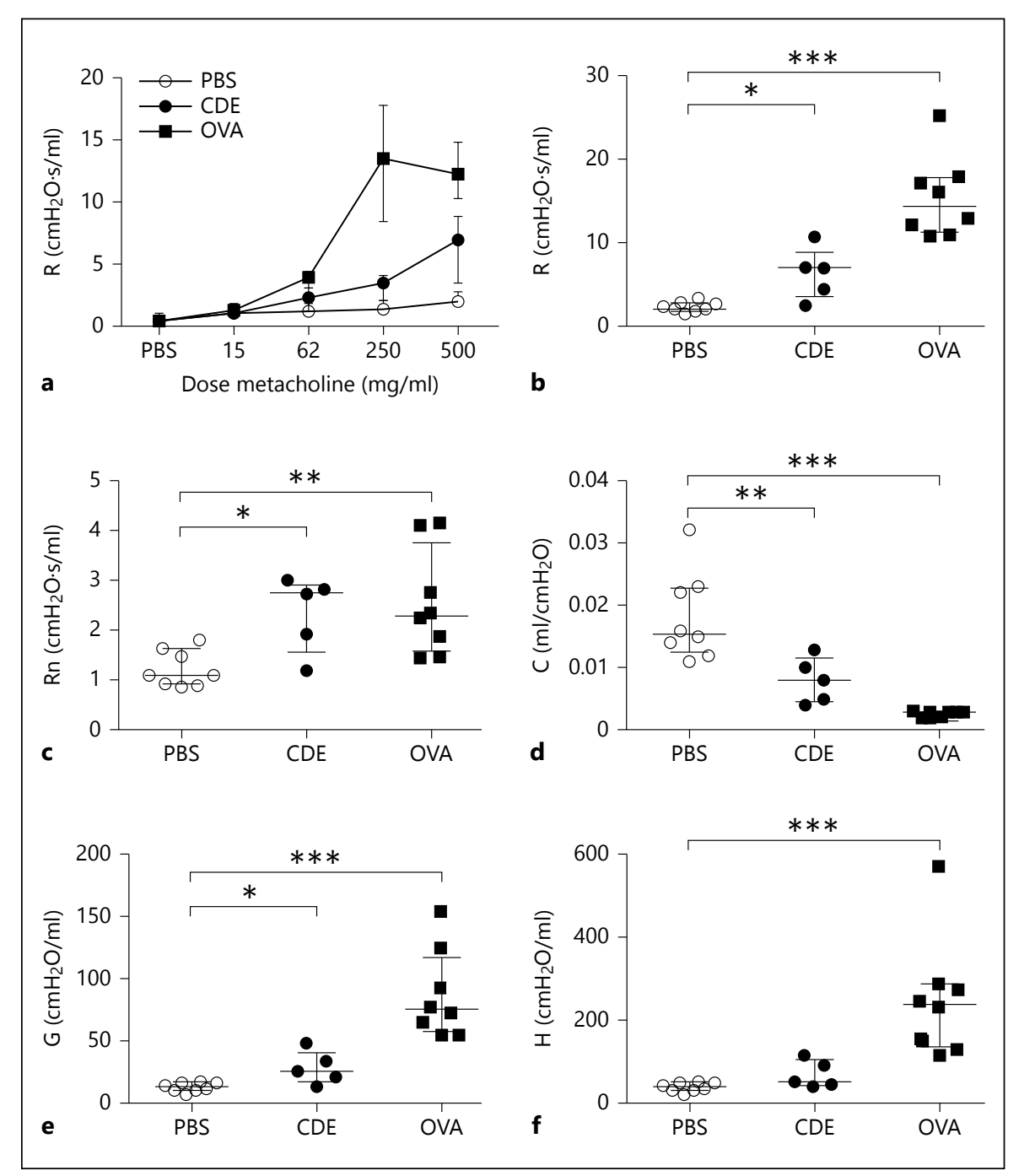

in lung tissue compared to PBS-challenged mice, as well as increased mRNA expression of IL-4 ( $p<0.05)$, but not of IL-5 (fig. 5a). Both CDE- and OVA-challenged mice had an increased expression of IFN- $\gamma$ mRNA compared to PBS-challenged mice ( $\mathrm{p}<0.01$ and 0.05 , respectively), and there was also a trend for increased IFN $-\gamma$ protein in both groups (fig. $5 b$ ). In mice challenged with CDE, the lung tissue levels of IL-17a were increased compared to PBS-challenged mice, which was also confirmed by mRNA analysis ( $\mathrm{p}<0.01$; fig. $5 \mathrm{c}$ ). OVA-challenged mice also had increased IL-17a expression ( $\mathrm{p}<0.01$ ), but to a lower level than CDE-challenged mice (fig. 5c). Taken together, the chronic presensitisation/challenge protocol resulted in different types of inflammation depending on which allergen (rFel d 1/CDE or OVA) was used.

\section{Serum Antibodies to Fel 1 and OVA}

The IgE response in the cat allergen- and OVA-sensitisation protocols to Fel d 1 and OVA, respectively, was measured in sera recovered at the end of the protocol (day 44). In mice presensitised to $\mathrm{rFel} \mathrm{d} 1$ and subsequently challenged with PBS, the Fel d 1-specific IgE levels were close to background levels. Elevated, although not significant, levels of Fel d 1-specific IgE were observed in $\mathrm{rFel} \mathrm{d} 1$ presensitised and $\mathrm{CDE}$-challenged animals (fig. 6a). High concentrations of OVA-specific IgE were observed in OVA-challenged mice (fig. 6a). Fel d 1 -specific IgG1 was induced only in CDE-challenged mice, while very low concentrations of allergen-specific $\operatorname{IgG1}$ were found in sera from PBS-challenged mice ( $\mathrm{p}<$ 0.01 ; fig. 6b). A similar response was seen for Fel d 1-specific IgG2a, although individual mice in the PBS-chal- 
Fig. 4. Infiltration of inflammatory cells in lungs from mice subjected to the main protocol $(n=7-8)$. Cell infiltration in BAL was determined by differential counting of May Grünwald-Giemsa-stained cells: macrophages (a), lymphocytes (b), eosinophils (c) and neutrophils (d). Inflammation and mucus in lung tissue was assessed by histology analysis of paraffin-embedded sections: representative sections of HE-stained tissue (e), and PAS-stained tissue (f) from PBS-, CDE- and OVA-challenged mice, as indicated. Inflammation score based on HE- (g) and PAS- (h) stained sections, as described in Materials and Methods. Mann-Whitney U test; * $\mathrm{p}<0.05,{ }^{* *} \mathrm{p}<$ $0.01,{ }^{* * *} \mathrm{p}<0.001$.

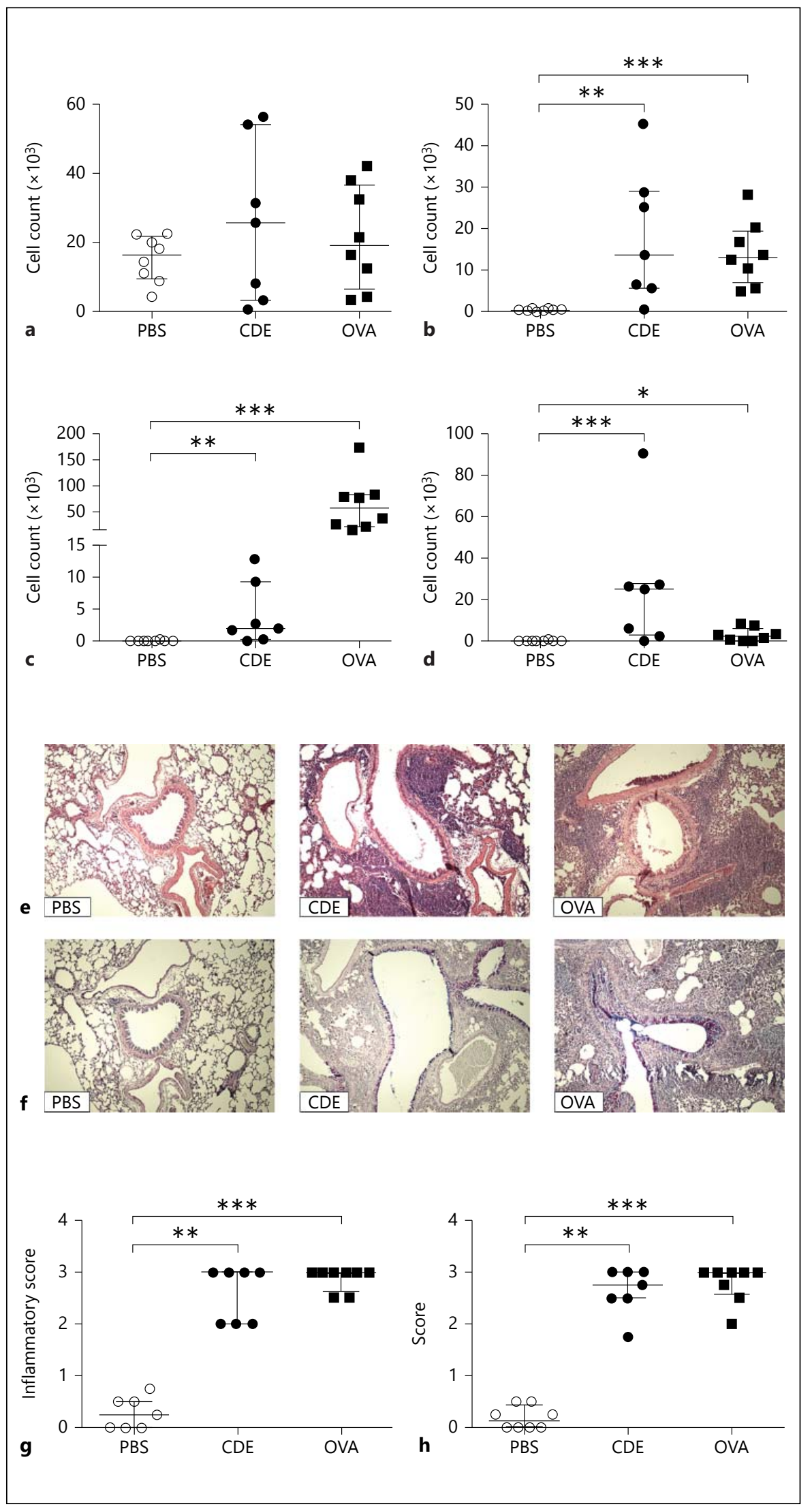

Int Arch Allergy Immunol 2014;165:195-205 


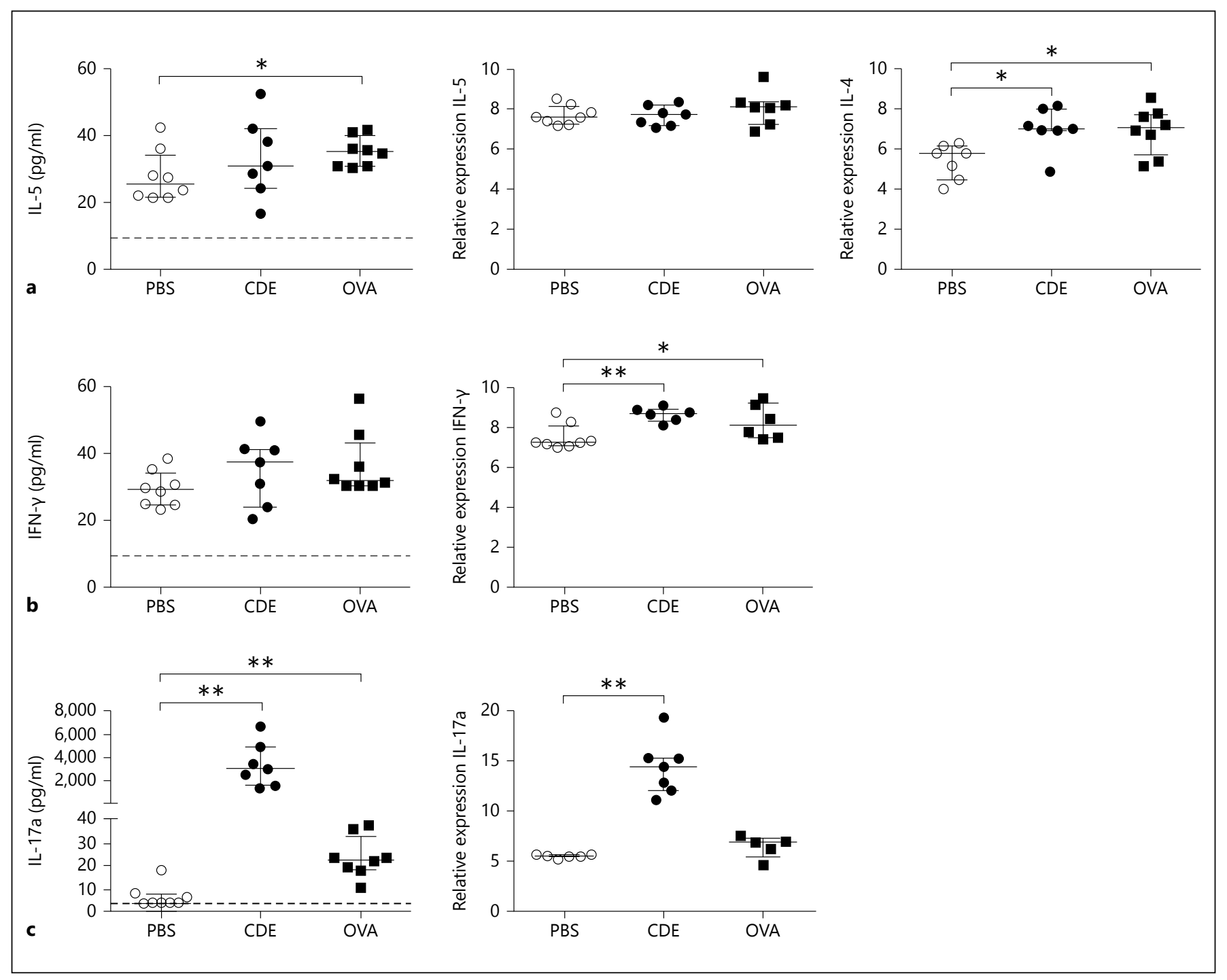

Fig. 5. Cytokines in lung tissue from mice subjected to the main protocol ( $\mathrm{n}=5-8)$. a Concentration of IL-5 (left) and relative expression of IL-5 (middle) and IL-4 (right) mRNA in lung tissue. b Concentration and relative expression of IFN- $\gamma$ in lung tissue. c Concentration and relative expression of IL-17a in lung tissue. IL- 5 and IFN- $\gamma$ concentrations were determined by ELISA, and IL-17a concentration was determined by Luminex. Mann-Whitney $\mathrm{U}$ test; ${ }^{*} \mathrm{p}<0.05,{ }^{* *} \mathrm{p}<0.01$. lenged groups had some induction of allergen-specific IgG2a ( $<<0.01$; fig. $6 \mathrm{c})$. The OVA presensitised and challenged mice all exhibited high levels of OVA-specific IgG1 and IgG2a (fig. 6b, c). The analyses of the antibody responses to Fel $\mathrm{d} 1$ and OVA revealed that both presensitisation and challenge protocols led to induction of specific IgE, IgG1 and IgG2a, although the OVA model exhibited the most pronounced Th2 profile of Ig subclasses. The Fel d 1-specific IgE evoked by presensitisation with $\mathrm{rFel} \mathrm{d} 1$ was sustained only in mice exposed to CDE airway challenge.

\section{Discussion}

Asthma is a heterogenic disease displaying a variety of phenotypes in humans [29]. This highlights the need for well-defined asthma models specifically suited for addressing disease mechanisms or for evaluating existing and novel therapies. Chronic sensitisation protocols have been reported to result in models of pronounced Th2type disease $[10-12,15]$, more mixed types of diseases $[14,30,31]$, and even dexamethasone insensitive disease [32]. Our cat allergen-induced asthma model exhibits 


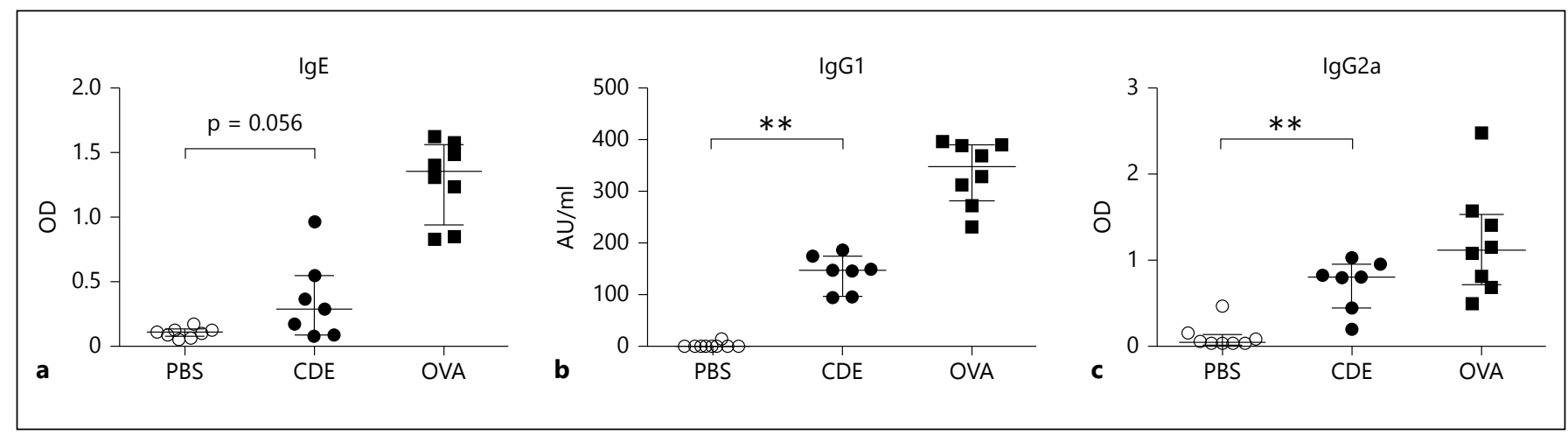

Fig. 6. Levels of antigen-specific Ig in serum at the end of the main protocol $(n=7-8)$. Analyses of Ig subclasses were performed with ELISA: IgE (a), IgG1 (b) and IgG2a (c). Mann-Whitney U test;
** $\mathrm{p}<0.01$. Note that the values for PBS mice refer to the Fel $d$ 1 -specific Ig and values for the OVA group were not included in the statistical comparison. characteristics of Th17/neutrophilic asthma with increased neutrophil numbers in BAL and increased levels of IL-17a in lung tissue. The model also shows characteristics of Th2-dependent disease as shown by enhanced levels of Fel d 1-specific serum IgE, increased eosinophil numbers in BAL, and increased IL-4 mRNA expression in lung tissue. The Th17/neutrophilic character of the airway inflammation observed in our model is indicative of a chronic type of experimental disease [30]. Such Th17/ neutrophilic type of inflammation has been reported to be Th2 independent and insensitive to dexamethasone treatment, similar to human non-eosinophilic asthma phenotypes that are linked to a poor response to corticosteroid treatment $[29,30]$. In contrast to the mixed response seen in the cat allergen model, the mice in our OVA model show a Th2 type of disease, manifested by an airway response dominated by eosinophil infiltration in BAL and Th2 inflammation in the lung tissue, as well as a strong OVA-specific IgE response in serum. This is in line with several acute and chronic experimental allergy and asthma OVA models [6]. Despite the different types of inflammation in the two models, AHR was increased at the end of both protocols, although the changes were generally more robust in the OVA model than in the cat allergy model.

Human allergic asthma is characterised by a chronic phase in which airway tissue remodelling takes place [33]. Similar lung tissue changes were found in both CDE- and OVA-challenged mice in our study. Both protocols induced perivascular and peribronchial invasion of inflammatory cells, mucous hyperplasia and medial hypertrophy of arterial walls, which was not observed in the PBSchallenged control mice. Multinuclear macrophages were found in the mice of both models and are a typical response to inhalation of foreign bodies [34]. Increased deposition of collagen surrounding the bronchi combined with mucous hyperplasia observed in both models suggests increased proliferation of bronchial epithelial cells following damage.

CDE was employed for the repeated i.n. challenges to obtain a chronic airway response. CDE reflects cat allergens in the form that humans are exposed to them by containing a mix of components, including different cat allergens and non-allergenic constituents that may have immune-activating or modulating properties. Non-allergen-specific immune stimulation has been shown to promote allergic responses to allergens, such as house dust mite and birch pollen $[35,36]$. The composition of the allergen source used for sensitisation and airway challenge is indeed critical for the establishment of chronic airway inflammation and AHR. This was illustrated in a study by Goplen et al. [13], who demonstrated that a mixture of two or three allergen extracts, from house dust mite, ragweed pollen and Aspergillus, generated chronic experimental asthma, as opposed to repeated airway challenge with any of the single allergens, which induced tolerance. In our chronic cat allergy model, CDE seems to include the factors needed for triggering an airway inflammatory response and AHR. In addition, we spiked the CDE with rFel $d 1$ in order to ensure that the target allergen was present in sufficient amounts. We used s.c. sensitisation of the mice with $\mathrm{rFel} \mathrm{d} 1$ adsorbed to alum prior to i.n. CDE challenges as, in this model, we have found that it is essential for the induction of a significant Fel d 1-specific Th2 response, allergic inflammation and AHR [unpubl. data]. 
The mixed type of immune response and airway inflammation detected in the cat allergy model may be promoted by LPS present in the CDE. In our model, the LPS content in CDE was at least 2.5-times higher than in OVA. A higher level of LPS present during sensitisation via the airway is known to promote a mixed type of inflammation with lung infiltration of neutrophils, while lower levels of LPS stimulate typical Th2 responses and eosinophilic inflammation [37]. In a study where different amounts of LPS were added to OVA applied via i.n. sensitisation, it was shown that high levels of LPS induced a non-eosinophilic airway inflammation and AHR that was dependent on IFN- $\gamma$ [38]. This experimental asthma phenotype could be correlated to more severe asthma, as neutrophilic inflammation and expression of IFN- $\gamma$ was higher in induced sputum from patients with severe asthma than from patients with mild to moderate asthma [38]. The same researchers also showed that in their model of asthma induced by i.n. sensitisation with LPS-contaminated OVA, the observed airway inflammation was dependent on IL-17 [39]. In addition, it has been reported that tolerisation to LPS prior to sensitisation can prevent eosinophilic infiltration in BAL [40]. It is thus likely that LPS, or other constituents of the CDE, promote the mixed type of airway response seen in our cat allergeninduced asthma model. In this context, it is also interesting to note that Fel $\mathrm{d} 1$ itself has been suggested to act as a non-specific immunostimulator by enhancing TLR2and TLR4-activation through binding to LPS [41].

In conclusion, here we have presented a chronic model for cat allergen-induced asthma. The model exhibits several hallmarks of chronic allergic asthma, such as AHR, a mixed airway inflammation and signs of remodelling of lung tissue. This model can be employed for the development of novel treatment strategies.

\section{Acknowledgements}

The authors thank Neda Bigdeli and Jonas Binnmyr for excellent technical assistance. This work was supported by grants from the Swedish Research Council, the Stockholm County Council, the Swedish Heart-Lung Foundation, the Swedish Asthma and Allergy Association's Research Foundation, the King Gustaf V 80th Birthday Foundation, the Hesselman Foundation, the Konsul Th. C. Bergh Foundation, the Centre for Allergy Research at Karolinska Institutet, and Karolinska Institutet.

\section{References}

1 Abramson MJ, Puy RM, Weiner JM: Injection allergen immunotherapy for asthma. Cochrane Database Syst Rev 2010;8:CD001186.

2 Niggemann B, Jacobsen L, Dreborg S, Ferdousi HA, Halken S, Host A, Koivikko A, Koller D, Norberg LA, Urbanek R, Valovirta E, Wahn U, Moller C: Five-year follow-up on the PAT study: specific immunotherapy and long-term prevention of asthma in children. Allergy 2006;61:855-859.

-3 Calderon MA, Demoly P, Gerth van Wijk R, et al: EAACI: a European declaration on immunotherapy - designing the future of allergen specific immunotherapy. Clin Transl Allergy 2012;2:20.

4 Casale TB, Stokes JR: Future forms of immunotherapy. J Allergy Clin Immunol 2011;127: 8-17.

5 Valenta R, Campana R, Marth K, van Hage M: Allergen-specific immunotherapy: from therapeutic vaccines to prophylactic approaches. J Intern Med 2012;272:144-157.

-6 Kumar RK, Herbert C, Foster PS: The 'classical' ovalbumin challenge model of asthma in mice. Curr Drug Targets 2008;9:485-494.

7 Kumar RK, Foster PS: Modeling allergic asthma in mice: pitfalls and opportunities. Am J Respir Cell Mol Biol 2002;27:267-272.

$\checkmark 8$ Kips JC, Anderson GP, Fredberg JJ, Herz U, Inman MD, Jordana M, Kemeny DM, Lotvall
J, Pauwels RA, Plopper CG, Schmidt D, Sterk PJ, van Oosterhout AJ, Vargaftig BB, Chung KF: Murine models of asthma. Eur Respir J 2003;22:374-382

-9 Fuchs B, Braun A: Improved mouse models of allergy and allergic asthma - chances beyond ovalbumin. Curr Drug Targets 2008;9:495502.

10 McMillan SJ, Lloyd CM: Prolonged allergen challenge in mice leads to persistent airway remodelling. Clin Exp Allergy 2004;34:497507.

11 Johnson JR, Wiley RE, Fattouh R, Swirski FK, Gajewska BU, Coyle AJ, Gutierrez-Ramos JC, Ellis R, Inman MD, Jordana M: Continuous exposure to house dust mite elicits chronic airway inflammation and structural remodeling. Am J Respir Crit Care Med 2004;169:378-385.

12 Wang Y, Li Y, Shan J, Fixman E, McCusker C: Effective treatment of experimental ragweedinduced asthma with STAT-6-IP, a topically delivered cell-penetrating peptide. Clin Exp Allergy 2011;41:1622-1630.

13 Goplen N, Karim MZ, Liang Q, Gorska MM, Rozario S, Guo L, Alam R: Combined sensitization of mice to extracts of dust mite, ragweed, and aspergillus species breaks through tolerance and establishes chronic features of asthma. J Allergy Clin Immunol 2009;123: 925-932.e911.
14 Kerzerho J, Maazi H, Speak AO, Szely N, Lombardi V, Khoo B, Geryak S, Lam J, Soroosh P, van Snick J, Akbari O: Programmed cell death ligand 2 regulates $\mathrm{T}_{\mathrm{H}} 9$ differentiation and induction of chronic airway hyperreactivity. J Allergy Clin Immunol 2013;131: 1048-1057.e2.

15 Chen ZG, Zhang TT, Li HT, Chen FH, Zou XL, Ji JZ, Chen H: Neutralization of TSLP inhibits airway remodeling in a murine model of allergic asthma induced by chronic exposure to house dust mite. PLoS One 2013; 8:e51268.

16 Kumar RK, Herbert C, Webb DC, Li L, Foster PS: Effects of anticytokine therapy in a mouse model of chronic asthma. Am J Respir Crit Care Med 2004;170:1043-1048.

17 McMillan SJ, Xanthou G, Lloyd CM: Therapeutic administration of budesonide ameliorates allergen-induced airway remodelling. Clin Exp Allergy 2005;35:388-396.

18 Fattouh R, Midence NG, Arias K, Johnson JR, Walker TD, Goncharova S, Souza KP, Gregory RC Jr, Lonning S, Gauldie J, Jordana M: Transforming growth factor- $\beta$ regulates house dust mite-induced allergic airway inflammation but not airway remodeling. Am J Respir Crit Care Med 2008;177:593-603.

19 Schou C: Defining allergens of mammalian origin. Clin Exp Allergy 1993;23:7-14. 
20 Plaschke P, Janson C, Norrman E, Bjornsson E, Ellbjar S, Jarvholm B: Association between atopic sensitization and asthma and bronchial hyperresponsiveness in Swedish adults: pets, and not mites, are the most important allergens. J Allergy Clin Immunol 1999;104: 58-65.

21 Ronmark E, Bjerg A, Perzanowski M, PlattsMills T, Lundback B: Major increase in allergic sensitization in schoolchildren from 1996 to 2006 in northern Sweden. J Allergy Clin Immunol 2009;124:357-363, 363.e1-15.

22 Gronlund H, Adedoyin J, Reininger R, Varga EM, Zach M, Fredriksson M, Kronqvist M, Szepfalusi Z, Spitzauer S, Gronneberg R, Valenta R, Hedlin G, van Hage M: Higher immunoglobulin $\mathrm{E}$ antibody levels to recombinant Fel d 1 in cat-allergic children with asthma compared with rhinoconjunctivitis. Clin Exp Allergy 2008;38:1275-1281.

23 Gronlund H, Saarne T, Gafvelin G, van Hage $\mathrm{M}$ : The major cat allergen, Fel d 1, in diagnosis and therapy. Int Arch Allergy Immuno 2010;151:265-274.

24 Neimert-Andersson T, Thunberg S, Swedin L, Wiedermann U, Jacobsson-Ekman G, Dahlen SE, Scheynius A, Gronlund $H$, van Hage M, Gafvelin G: Carbohydrate-based particles reduce allergic inflammation in a mouse model for cat allergy. Allergy 2008;63: 518-526.

-25 Saarne T, Neimert-Andersson T, Gronlund $H$, Jutel M, Gafvelin G, van Hage M: Treatment with a Fel d 1 hypoallergen reduces allergic responses in a mouse model for cat allergy. Allergy 2011;66:255-263.

-26 Grundstrom J, Neimert-Andersson T, Kemi C, Nilsson OB, Saarne T, Andersson M, van Hage M, Gafvelin G: Covalent coupling of vitamin D3 to the major cat allergen Fel d 1 improves the effects of allergen-specific immunotherapy in a mouse model for cat allergy. Int Arch Allergy Immunol 2012;157:136146.
27 Thunberg S, Neimert-Andersson T, Cheng Q, Wermeling F, Bergstrom U, Swedin L, Dahlen SE, Arner E, Scheynius A, Karlsson MC, Gafvelin G, van Hage M, Gronlund H: Prolonged antigen-exposure with carbohydrate particle based vaccination prevents allergic immune responses in sensitized mice. Allergy 2009;64: 919-926.

28 Gronlund H, Bergman T, Sandstrom K, Alvelius G, Reininger R, Verdino P, Hauswirth A, Liderot K, Valent P, Spitzauer S, Keller W, Valenta R, van Hage-Hamsten M: Formation of disulfide bonds and homodimers of the major cat allergen Fel d 1 equivalent to the natural allergen by expression in Escherichia coli. J Biol Chem 2003;278:40144-40151.

29 Bhakta NR, Woodruff PG: Human asthma phenotypes: from the clinic, to cytokines, and back again. Immunol Rev 2011;242:220-232.

-30 Zhao J, Lloyd CM, Noble A: Th17 responses in chronic allergic airway inflammation abrogate regulatory $\mathrm{T}$-cell-mediated tolerance and contribute to airway remodeling. Mucosal Immunol 2013;6:335-346.

1 Fogli LK, Sundrud MS, Goel S, Bajwa S, Jensen K, Derudder E, Sun A, Coffre M, Uyttenhove C, van Snick J, Schmidt-Supprian M, Rao A, Grunig G, Durbin J, Casola S, Rajewsky K, Koralov SB: T cell-derived IL-17 mediates epithelial changes in the airway and drives pulmonary neutrophilia. J Immunol 2013;191:3100-3111.

32 Duechs MJ, Tilp C, Tomsic C, Gantner F, Erb KJ: Development of a novel severe triple allergen asthma model in mice which is resistant to dexamethasone and partially resistant to TLR7 and TLR9 agonist treatment. PLoS One 2014;9:e91223.

33 Holgate ST, Davies DE, Powell RM, Howarth PH, Haitchi HM, Holloway JW: Local genetic and environmental factors in asthma disease pathogenesis: chronicity and persistence mechanisms. Eur Respir J 2007;29:793-803.

34 Renne R, Brix A, Harkema J, Herbert R, Kittel B, Lewis D, March T, Nagano K, Pino M, Rittinghausen S, Rosenbruch $\mathrm{M}$, Tellier $\mathrm{P}$, Wohrmann T: Proliferative and nonproliferative lesions of the rat and mouse respiratory tract. Toxicol Pathol 2009;37:5S-73S.
35 Hammad H, Chieppa M, Perros F, Willart MA, Germain RN, Lambrecht BN: House dust mite allergen induces asthma via Tolllike receptor 4 triggering of airway structural cells. Nat Med 2009;15:410-416.

36 Traidl-Hoffmann C, Mariani V, Hochrein H, Karg K, Wagner H, Ring J, Mueller MJ, Jakob $\mathrm{T}$, Behrendt H: Pollen-associated phytoprostanes inhibit dendritic cell interleukin-12 production and augment T helper type 2 cell polarization. J Exp Med 2005;201:627-636.

37 Eisenbarth SC, Piggott DA, Huleatt JW, Visintin I, Herrick CA, Bottomly K: Lipopolysaccharide-enhanced, Toll-like receptor 4-dependent $\mathrm{T}$ helper cell type 2 responses to inhaled antigen. J Exp Med 2002;196:16451651.

38 Kim YK, Oh SY, Jeon SG, Park HW, Lee SY, Chun EY, Bang B, Lee HS, Oh MH, Kim YS, Kim JH, Gho YS, Cho SH, Min KU, Kim YY, Zhu Z: Airway exposure levels of lipopolysaccharide determine type 1 versus type 2 experimental asthma. J Immunol 2007;178:53755382.

39 Kim YS, Hong SW, Choi JP, Shin TS, Moon HG, Choi EJ, Jeon SG, Oh SY, Gho YS, Zhu Z, Kim YK: Vascular endothelial growth factor is a key mediator in the development of T cell priming and its polarization to type 1 and type $17 \mathrm{~T}$ helper cells in the airways. J Immunol 2009; 183:5113-5120.

40 Natarajan S, Kim J, Bouchard J, Cruikshank W, Remick DG: Pulmonary endotoxin tolerance protects against cockroach allergen-induced asthma-like inflammation in a mouse model. Int Arch Allergy Immunol 2012;158: 120-130.

-41 Herre J, Gronlund H, Brooks H, Hopkins L, Waggoner L, Murton B, Gangloff M, Opaleye O, Chilvers ER, Fitzgerald K, Gay N, Monie T, Bryant C: Allergens as immunomodulatory proteins: the cat dander protein Fel $\mathrm{d} 1$ enhances TLR activation by lipid ligands. J Immunol 2013;191:1529-1535. 